p911 Eggs-tra evidence: Scientists set high burden of proof for fertility finding.

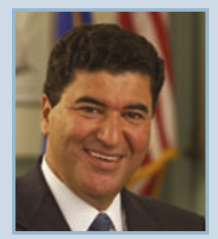

p914 Under fire: NIH scientists say they feel punished for the misdeeds of a few colleagues.

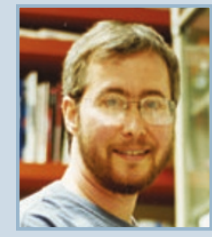

p916 Rebel with a cause: Transgendered researcher Ben Barres fights for women in science.

\title{
Threat of pandemic brings flu drug back to life
}

With an effective avian influenza vaccine nowhere on the horizon, health officials are scrambling for ways to head off a pandemic. Governments have been purchasing millions of doses of Roche's Tamiflu, but would that alone be enough to head off a pandemic? Should other drugs be stockpiled? Are other drugs available?

The influenza drug Relenza, available since 1999, had been a footnote to Tamiflu but, after glowing reports in August of its relative effectiveness, has jumped back into the spotlight.

Relenza, marketed by GlaxoSmithKline, and Roche's Tamiflu both bind to the active site of the virus' neuraminidase protein, rendering the virus unable to escape its host cell and infect others.

In August Germany announced it would buy 1.7 million doses of Relenza as part of its bird flu preparedness strategy. "Germany's purchase shows that countries are starting to take a balanced view of influenza preparedness," says Simon Tucker, head of research at Melbournebased Biota, which developed Relenza.

Bulk orders of Tamiflu from the UK, France and other countries to cover $20 \%$ or more of their population are pushing Roche's production capacity to the limit. But Relenza, which was the first neuraminidase inhibitor on the market, claims only one percent of the growing flu drug market. The drug has suffered from lackadaisical marketing efforts, according to a lawsuit that Biota, which gets a percentage of sales, is bringing against GlaxoSmithKline.

Relenza has also been unpopular in part because it must be breathed in with an inhaler. GlaxoSmithKline is considering repackaging Relenza as a shot or nebulizer to increase sales.

Relenza is at least as effective as Tamiflu and has fewer side effects, including nausea and headaches, according to an article published 13 August (Lancet 366, 533-534; 2005). The report, based on data compiled from the companies' clinical trials and from subsequent studies, also says there is no evidence of resistance to Relenza, compared with resistance levels of up to $18 \%$ in those taking Tamiflu (Lancet 364, 759-765; 2004). The researchers recommend stockpiling both.

The Tamiflu resistance data are based on studies in Japan, which in past years has consumed nearly $75 \%$ of the drug's worldwide supply.
Other influenza drugs, such as amantadine, have already been rendered ineffective against bird flu by misuse (Nature 435, 1009; 2005).

"In a pandemic situation, resistance is a major concern," says University of Wisconsin virologist Yoshihiro Kawaoka, who led the study in Japan. He adds that Relenza has not been used widely enough to judge its potential for creating resistance. "It has been underestimated," he says.

Meanwhile, Biota is conducting phase 1 trials, boosted by a $\$ 5.5$ million National Institutes of Health grant, of a neuraminidase inhibitor that could be taken only once a week-compared with twice a day for Relenza and Tamiflu.

But will any-or a combination-of the drugs help? A pandemic virus would require quick access to the drugs. After the first few days of infection, says Graeme Laver, whose work led to the design of neuraminidase inhibitors, "you may be able to stop the virus, but the immune response would likely kill you." To prevent misuse of the drugs, he adds, they should be sold in tandem with an influenza diagnostic test.

David Cyranoski, Tokyo

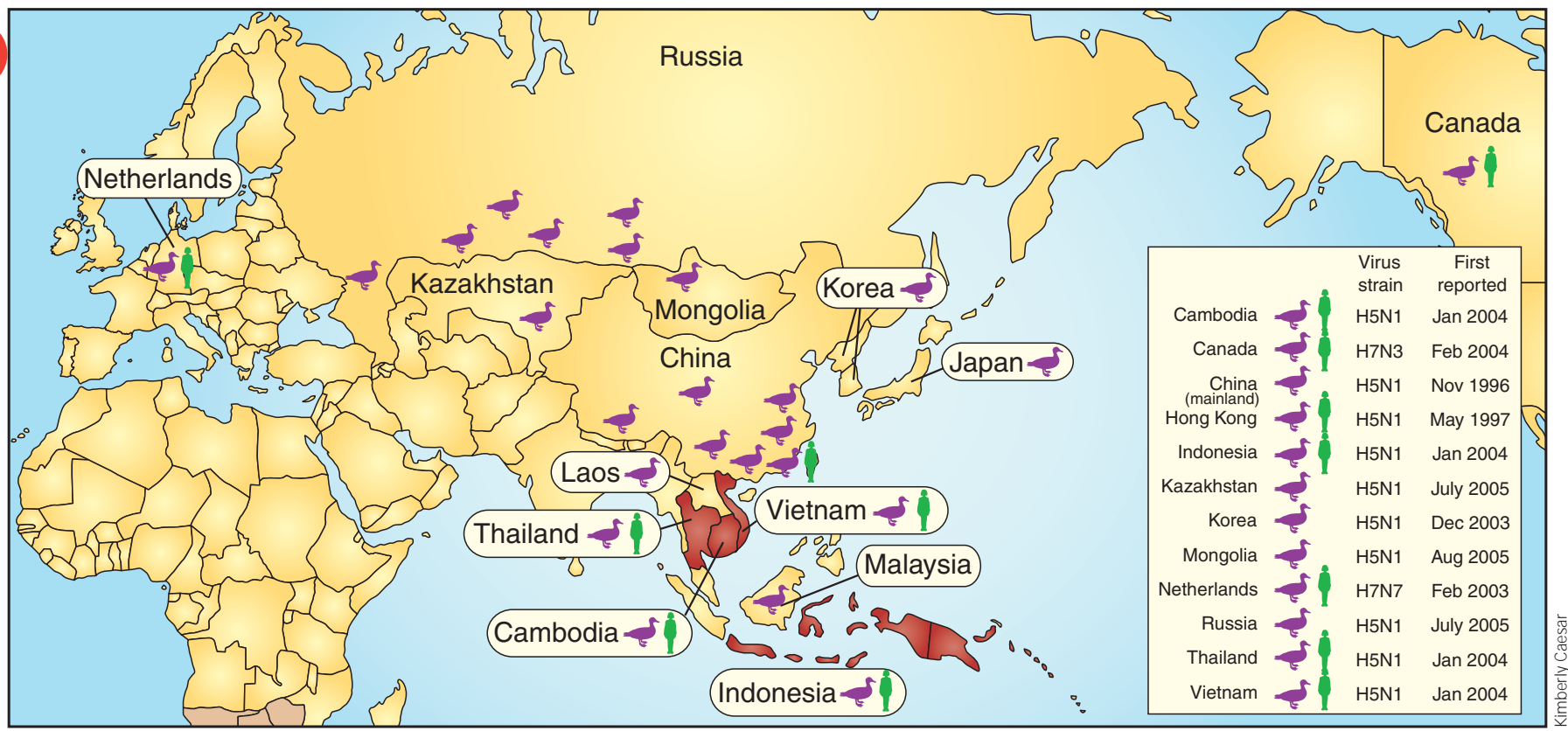

Room to roam: With unpredictable migratory routes, the $\mathrm{H} 5 \mathrm{~N} 1$ virus-which has caused the death or destruction of more than 150 million birds in southeast Asia-is spreading toward Europe. Kazakhstan, Russia, Mongolia and Tibet are the latest to register cases. 